\title{
Acute Respiratory Distress Syndrome in Children: Duration of Ventilation and Mortality
}

\section{Rodriguez-Moya Valentín $S^{1}$, López-González Lissette $R^{2}$, Díaz-Casañas Elaine ${ }^{3 *}$, Verdecia Sánchez Leonor ${ }^{4}$ and Ramirez Morejón Amilcar ${ }^{5}$}

${ }^{1}$ Department of Pediatrics, General Teaching Hospital "Martin Chan Puga", Camaguey, Cuba

${ }^{2}$ Intensive Care Unit, Juan Manuel Márquez Pediatric Hospital, Havana, Cuba

${ }^{3}$ National Agricultural Health Center, Mayabeque, Cuba

${ }^{4}$ Intensive Care Unit, Juan Manuel Márquez Pediatric Hospital, Havana, Cuba

${ }^{5}$ Department of Pharmacology, University of Medical Sciences "Carlos J. Finlay", Camaguey, Cuba

*Corresponding Author: Elaine Díaz-Casañas, National Agricultural Health Center, Jamaica Highway and National Highway, San José de las Lajas, Mayabeque, Cuba.

Received: August 06, 2019; Published: September 30, 2019

DOI: 10.31080/ASPE.2019.02.0156

\begin{abstract}
Introduction: Acute respiratory distress syndrome is a disease with severe, progressive and irreversible hypoxemia, of multicausal origin, rare in pediatric intensive units but with high mortality due to multiple organ failure caused by prolonged oxygen deficiency. Objective: To determine the relationship between demographic and clinical variables with the duration of mechanical ventilation and mortality of acute respiratory distress syndrome in children.

Materials and Methods: Retrospective study of patients admitted to 15 pediatric intensive care units in 13 provinces of Cuba, which were diagnosed with acute respiratory distress, according to the Rome consensus, in the period from January 2016 to December 2018. The data were obtained from each patient's clinical records. Demographic variables, clinical forms of acute respiratory distress syndrome, duration of mechanical ventilation and mortality were evaluated. Qualitative variables are shown in frequency tables by numbers and per cents, in the quantitative variables the classic analysis associated with contingency tab, such as Pearson's ji-square and comparison of stockings.

Results: 282 patients were recorded in the period, $63.7 \%$ under the age of six, 54.4\% of the male sex and 51.1\% of white skin. Clinical forms of lung prevailed (58.1\%) and correlate ( $\mathrm{p}-0.022)$ with survival, the median duration of mechanical ventilation was 10 days. There is a ratio ( $\mathrm{p}-0.000$ ) between ventilation duration and mortality. An overall mortality of $40.78 \%$ ( $\mathrm{-115}$ ) was reported. Conclusions: The acute respiratory distress syndrome has a higher incidence in those under the age of six, in clinical forms of the lungs, which are associated with greater survival, which rises as they increase days of mechanical ventilation.

Keywords: Acute Respiratory Distress Syndrome; Hypoxemia; Children
\end{abstract}

\section{Abbreviations}

ARDS: Acute Respiratory Distress Syndrome; UCIP: Paediatric Intensive Units; FMO: Multiple Organ Failure; AECC: American-European Consensus Conference; VAM: Mechanical Artificial Ventilation

\section{Introduction}

Acute respiratory distress syndrome is a heterogeneous etiology and pathophysiology entity that is severe, progressive and irreversible hypoxemia [1]. For your diagnosis are combined clinical, hemodynamic and oxygenation criteria who were endorsed in Ecc [2] used for many years to identify and treat ARDS in both adult and pediatric patients.

From the update of the last definition for adults [3] and with the need to reduce invasiveness, in addition to promoting early diagno- sis, the first Consensus Conference on Pediatric Acute Lung Damage, with 132 recommendations of high strength in its scientific evidence [4].

The treatment is part of the identification, control and treatment of the trigger and in the mechanical artificial ventilation, the latter with the aim of preserving the arterial saturation of oxygen and avoid complications by the increase airway pressures $[5,6]$.

Reports from the United States, Australia, Europe and New Zealand indicate that the incidence of ARDS in the pediatric population is 2 to 12.8 per 100000 patients per year and mortality is found between $27 \%$ and $35 \%$ [5,7]. Other authors, in different regions incidence of $0.8 \%$ to $4.4 \%$ and mortality above $50 \%[6,8]$. A 10 -year job at a UCIP Cuba, report or $3.6 \%$ with overall mortality of $36.7 \%$ 
[9]. These papers show that mortality is increased as a result of the WFO it's the consequence severe hypoxemia.

In order to determine the relationship between demographic and clinical variables with the duration of mechanical ventilation and mortality of SDRA, this research was carried out.

\section{Materials and Methods}

A retrospective study was conducted on patients admitted to 15 UCIP in 13 provinces of Cuba, which were diagnosed with SDRA, according to the consensus of acute lung damage [4] in the period from January 2016 to December 2018. The data were obtained from each patient's clinical records. The design of the research, the recording and processing of the data was carried out according to the ethical principles for medical research in humans (Helsinki Declaration) [10] amended by the 64th General Assembly of the World Medical Association, Fortaleza, Brazil, October 2013.
Demographic variables, clinical forms of ARDS, duration of Va $\mathrm{M}$ and mortality were evaluated. Data processing was performed using the IBM SPSS Statistics 21 compute analytical system; were considered significant differences when the page is 0.05 . For processing and statistical analysis qualitative variables are shown in frequency tables by numbers and percents, in quantitative variables the classic analysis associated with contingency tables, such as Pearson's ji-square and mean comparison, was used.

\section{Results and Discussion}

Table 1 shows the demographic characteristics of patients and clinical forms of ARDS on diagnosis, a total of 282 patients in the three years were included in the study, a slight decrease in the incidence of ARDS 2018 (28\%) compared to previous years, (32.6\% in 2016; 39.45 in 2017), which could be the result of the introduction to the country of new technologies for oxygen therapy and the noninvasive ventilation, which offer clinical tolerance and decreases the need for invasiveness, especially in the patient under the age of five.

\begin{tabular}{|c|c|c|c|c|c|c|c|c|c|}
\hline \multirow{2}{*}{\multicolumn{2}{|c|}{ Patient characteristics }} & \multicolumn{2}{|c|}{ Year $2016(\mathrm{~N}-92)$} & \multicolumn{2}{|c|}{ Year 2017 (No. 111) } & \multicolumn{2}{|c|}{ Year 2018 (No.79) } & \multicolumn{2}{|c|}{ Total (No. 282) } \\
\hline & & \multirow{2}{*}{$\begin{array}{c}\mathbf{n} \\
24\end{array}$} & \multirow{2}{*}{$\begin{array}{c}\% \\
26.1\end{array}$} & \multirow{2}{*}{$\begin{array}{c}\mathbf{n} \\
43\end{array}$} & \multirow{2}{*}{$\begin{array}{c}\% \\
38.7 \\
\end{array}$} & \multirow{2}{*}{$\begin{array}{c}\mathbf{n} \\
16\end{array}$} & \multirow{2}{*}{$\begin{array}{c}\% \\
20.2\end{array}$} & \multirow{2}{*}{$\begin{array}{c}\mathbf{n} \\
83\end{array}$} & \multirow{2}{*}{$\begin{array}{c}\% \\
29.4\end{array}$} \\
\hline Age (years) & $<1$ & & & & & & & & \\
\hline \multirow{3}{*}{$\mathrm{p}=0.384$} & Between 1 and 5 & 30 & 32.6 & 37 & 33.3 & 30 & 37.9 & 97 & 34.4 \\
\hline & $\begin{array}{l}\text { Between } 6 \text { and } \\
10\end{array}$ & 16 & 17.4 & 11 & 9.9 & 12 & 15.2 & 39 & 13.8 \\
\hline & $>10$ & 22 & 23.9 & 20 & 18.0 & 21 & 26.6 & 63 & 22.3 \\
\hline \multirow{2}{*}{$\begin{array}{l}\text { Sex } \\
p=0.234\end{array}$} & Female & 39 & 42.4 & 43 & 38.7 & 34 & 43.0 & 116 & 41.1 \\
\hline & Male & 53 & 57.6 & 68 & 61.3 & 45 & 56.9 & 166 & 58.9 \\
\hline \multirow{2}{*}{$\begin{array}{l}\text { Skin color } \\
\mathrm{p}=0.946\end{array}$} & blanca & 46 & 50.0 & 58 & 52.2 & 40 & 50.6 & 144 & 51.1 \\
\hline & Black & 46 & 50.0 & 53 & 47.7 & 39 & 49.4 & 138 & 48.9 \\
\hline \multirow{2}{*}{$\begin{array}{l}\text { SDRA Clinical Forms } \\
\mathrm{p}=0.083\end{array}$} & Pulmonary & 45 & 48.9 & 71 & 63.9 & 48 & 60.7 & 164 & 58.1 \\
\hline & Extrapulmonares & 47 & 51.1 & 40 & 36.0 & 31 & 39.2 & 118 & 41.8 \\
\hline
\end{tabular}

Table 1: Demographic and clinical activities of the patients included.

The highest incidence age group was the age of six with $63.8 \%$, the mean age was five years. This one result matches those of Garza Alatorre., et al. [11] And may be related to the fact that at these ages there is immaturity of the immune system given by deficiencies of lactoferrins, lysozymes, diphenism's, collections and immunoglobulins and as a result are more susceptible to serious infections than compromise the lives of these patients $[5,7]$.

As for sex, there was a slight predominance of males, which is in correspondence with several jobs that consider the male sex as one of the risk factors of ARDS in children [12.13]. According to the International Classification of Diseases, in its ninth review, being male is associated with a higher mortality rate from ARDS, which may be due to genetic factors or harm differences onals [14]. In this work, gender distribution is equitable ( $\mathrm{p}-0.374)$ between survivors and non-survivors.

Con relation to skin color there are no differences, result similar to previous work done in Cuba by this research team [9] table 2 shows the relationship between age groups and clinical forms, highlighting the fact that younger groups (under six years of age) significantly affect the clinical forms of ARDS, agreeing with other studies, which describes that pneumonia and sepsis are the most common $[7,15,16]$. It is known that most diseases that cause acute lung damage, in which more than one etiological factor converges the aggressor injury creates an exaggerated pulmonary inflammatory response, both humoral and cellular. The main humoral response includes activation of local cytokines, cell response includes 
lymphocytes, monocytes and neutrophils [17]. These humoral and cellular factors interact with each other and with increased adhesion molecules in the blood, which adhere to leukocytes, platelets and endothelial cells and induce rolling neutrophils, fibrin aggregates and platelets that obstruct capillary blood flow [16-18].

\begin{tabular}{|l|c|c|c|c|c|}
\hline \multirow{2}{*}{$\begin{array}{c}\text { SDRA Clinical } \\
\text { Forms }\end{array}$} & \multicolumn{5}{|c|}{ Age group (years) } \\
\cline { 2 - 6 } & $\mathbf{1}$ out of $\mathbf{1}$ & $\mathbf{1 - 5}$ & $\mathbf{6}-\mathbf{1 0}$ & $\mathbf{> 1 0}$ & Total \\
\hline Pulmonary & 48 & 68 & 23 & 25 & 164 \\
\hline Extrapulmonares & 35 & 29 & 16 & 38 & 118 \\
\hline Total & 83 & 97 & 39 & 63 & 282 \\
\hline Pearson Chi-square 14,539 p.0. 002 \\
\hline
\end{tabular}

Table 2: Distribution of patients according to the age groups and clinical forms of THE EDS. Contingency table.

Of the total number of patients included in the study, survivors predominated in clinical forms of lung with significant results $(\mathrm{p}$ - 0.022), which can be seen in table 3. In ARDS, in general, a high mortality is referred to in the pediatric population, as determined by the organic dysfunction that is triggered by a decrease in tissue oxygen availability, which gives net effect to the injury irreversible hypoxic cell phone $[18,19]$. The work of Emerald G [20] and Valentine, [21] report $52 \%$ and $58 \%$ mortality respectively, in patients whose ARDS was caused by extrapulmonary or systemic clinical forms. These cases are related to a multiorgan failure involving systemic endothelial and pulmonary capillary injury, which makes clinical evolution unfavorable with increased mortality [22]. Some authors pose mortality above or equal to $50 \%$, despite all treatment strategies $[6,19,23]$.

\begin{tabular}{|l|c|c|c|c|c|c|}
\hline \multirow{2}{*}{ Survival } & \multicolumn{3}{|l|}{ Clinical forms of the SDRA } & \multicolumn{2}{|c|}{ Total } \\
\cline { 2 - 7 } & Extrapulmonares & \multicolumn{2}{|c|}{ Pulmonary } & \\
\cline { 2 - 7 } & $\mathbf{n}$ & $\mathbf{0}$ & $\mathbf{n}$ & $\mathbf{\%}$ & $\mathbf{n}$ & $\mathbf{\%}$ \\
\hline Deceased & 59 & 20,9 & 56 & 19,9 & 115 & 40,8 \\
\hline Survivors & 59 & 20,9 & 108 & 38,3 & 167 & 59,2 \\
\hline Total & 118 & 41,8 & 164 & 58,2 & 282 & 100,0 \\
\hline
\end{tabular}

Table 3: Relationship between survival and clinical forms of ARDS.

Although some researchers hypothesize that mortality should be higher in patients with direct lung injury, $[3,24]$ in a meta-analysis by Agarwal., et al. [25] It was demonstrated that there are no differences in mortality between PATIENTS with ARDS in their pulmonary clinical forms compared to extrapulmonary patients of the disease. We consider that the proper diagnosis and treatment of patients, from primary health care, is a primary link to take into account for the correct prophylaxis of this disease, in which they combine so much lung factors such as systemic.

As for the duration of the MVA the average was 13.8 days and the median of 10 days, when analyzing its relationship with survival it was found that the days of mechanical ventilation were kept rel survival (p-0.000), the more days the patient is in UCIP, the more likelihood are to survive, results that coincide with other jobs $[7,9,14]$. Inflammatory mediators what And released during the course of the SDRA can have a very different impact on the gaseous exchange: while some produce bronchoconstriction, others cause pulmonary vasoconstriction that increases the rate of blood flow through the lungs, reducing the time for gaseous exchange in the socket. If this pulmonary vasoconstriction affects the precapillary sphincter, pulmonary blood flow will be reduced, which could reduce the production of pulmonary edema [26]. Mediators affecting the postcapillary sphincter induce stasis in the pulmonary capillary, with increased capillary pressure and pulmonary edema $[22,26,27]$.

The authors consider that the acute phase of ARDS is the one that gives the greatest risk to die, at this stage the hemodynamic instability, given by the different stages of sepsis, associated with refractory, severe and progressive hypoxemia are decisive in the course of the disease. Vital importance should be given to the identification and treatment of alarm signs from primary health care in this type of patient, if this messy inflammatory cascade can be curbed and oxygenation values stabilized, in the lowest possible time, with all the strategies that are protocolized, vital signs will be better recovered and survival will be greater.

\section{Conclusion}

ARDS has a higher incidence in children under six years of age, in clinical pulmonary forms, which are associated with increased survival, which rises as the days of mechanical ventilation increase.

\section{Acknowledgements}

We thank all the clinical researchers who participated in the collection of primary data of the included patients, they are: Dr Yandy León de Armas, Dr. Jorge Luis Ricardo Estupiñan, Dr. Dayvi García Campaña, Dr. Yamilet Segredo Molina, Dr. Erdwis Pérez Pintado, Dr. Frank Felipe Martin, D ra. Glenis Morales Torres, Dr. Yuneska Rodríguez Ochoa, Dr. Carlos Ascanio Rodríguez, Dr. Reynaldo Delgado Ravelo, Dr. Laura M. Sánchez Pérez, Dr. Osvaldo Mario Hidalgo Leyva, Dr. Jorge Enrique Padrón Alvares, Dr. Luz María del Toro Arce, Dr. Roxana Simón Suarez.

\section{Conflict of Interest}

The authors state that there are no conflicts of interest. 


\section{Bibliography}

1. Ashbaugh DG., et al. "Acute respiratory distress in adults". Lancet 2.7511 (1967): 319-323.

2. Bernard GR., et al. "The American-European Consensus Conference on ARDS. Definitions, mechanisms, relevant outcomes, and clinical trial coordination". American Journal of Respiratory and Critical Care Medicine 149.3-1 (1994): 818-24.

3. De Luca D., et al. "The use of the Berlin definition for acute respiratory distress syndrome during infancy and early childhood: multicenter evaluation and expert consensus". Intensive Care Medicine 39.12 (2013):2083-2091.

4. Pediatric Acute Lung Injury Consensus Conference Group. "Pediatric acute respiratory distress syndrome: consensus recommendations from the Pediatric Acute Lung Injury Consensus Conference." Pediatric Critical Care Medicine 16.5 (2015): 428-439.

5. Flori H., et al. "Comorbidities and assessment of severity of pediatric acute respiratory distress syndrome: proceedings from the Pediatric Acute Lung Injury Consensus Conference”. Pediatric Critical Care Medicine 16.5-1(2015): S41-S50.

6. Carrillo-Esper R., et al. "Evolución de la definición del síndrome de insuficiencia respiratoria aguda". Medicina Interna de México 34.4 (2018): 594-600.

7. Khemani RG., et al. "Pediatric Acute Respiratory Distress Syndrome: definition, incidence and epidemiology: proceedings from the Pediatric Acute Lung Injury Consensus Conference". Pediatric Critical Care Medicine 16.5-1 (2015): S23-S40.

8. Cardinal-Fernández P., et al. "Distrés respiratorio agudo: del síndrome a la enfermedad”. Medicina Intensiva 40.3 (2016): 169-175.

9. Rodríguez Moya VS., et al. "Incidencia y mortalidad del síndrome de dificultad respiratoria aguda”. AMC 19.3 (2015).

10. Declaración de Helsinki de la Asociación Médica Mundial. "Principios éticos para las investigaciones médicas en seres humanos". Junio 1964. Enmendada por la 64 a Asamblea General, Fortaleza, Brasil, octubre (2013).

11. Garza Alatorre A., et al. "Prevalencia del Síndrome de Dificultad Respiratoria Aguda en una unidad de cuidados intensivos pediátrica polivalente". Medicina Universitaria 14.54 (2012):11-15.

12. Kesecioglu J., et al. "Exogenus natural surfactant for treatment of acute lung injury and the acute respiratory distress syndrome". American Journal of Respiratory and Critical Care Medicine 180.10 (2009):989-994.
13. Halbertsma FJJ., et al. "Use of recruitment maneuvers during mechanical ventilation in pediatric and neonatal intensive care units in the Netherland". Intensive Care Medicine 33.9 (2007):1673-1674.

14. Sharif N., et al. "Factors associated within 28 days inhospitalmortality of patients with acute respiratory distress syndrome". BioMed Research International (2013): 547-564.

15. Wong JJ., et al. "Epidemiology of pediatric acute respiratory distress syndrome in Singapore: risk factors and predictive respiratory indices for mortality". Frontiers in Pediatrics 2.78 (2014).

16. Tamburro RF., et al. "Pediatric Acute Lung Injury Consensus Conference Group. Pulmonary specific ancillary treatment for pedaitric acute respiratory distress syndrome: proceedings from the Pediatric Acute Lung Injury Consensus Conference”. Pediatric Critical Care Medicine 16.5 -1 (2015): S61-S72.

17. Philipe J., et al. "Pediatric Acute Respiratory Distress Syndrome. Consensus Recommendations from the Pediatric Acute Lung Injury Consensus Conference". Pediatric Critical Care Medicine 16 (2015): 428-439.

18. Lorente JA., et al. "Acute respiratory distress syndrome in patients with and without diffuse alveolar damage: An autopsy study". Intensive Care Medicine 41.11(2015):1921-1930.

19. Quasney MW., et al. "The outcome of children with pediatric acute respiratory distress syndrome: proceedings from the Pediatric Acute Lung Injury Consensus Conference". Pediatric Critical Care Medicine 16.5 -1 (2015): S118-S131.

20. Emeriaud G., et al. "Monitoring of children with pediatric acute respiratory distress syndrome: proceedings from the Pediatric Acute Lung Injury Consensus Conference". Pediatric Critical Care Medicine 16.5-1(2015): S86-S101.

21. Valentine SL., et al. "Nonpulmonary treatment for pediatric acute respiratory distress syndrome: proceedings from the Pediatric Acute Lung Injury Consensus Conference". Pediatric Critical Care Medicine 16.5-1 (2015): S73-S85.

22. Rimensberger PC., et al. "Ventilatory support in children with pediatric acute respiratory distress syndrome: proceedings from the Pediatric Acute Lung Injury Consensus Conference". Pediatric Critical Care Medicine 16.5-1(2015): S51-S60.

23. Kao KC., et al. "Diffuse alveolar damage associated mortality in selected acute respiratory distress syndrome patients with open lung biopsy". Critical Care 19 (2015): 228-234.

24. Zhu YF., et al. "Mortality and morbidity of acute hypoxemic respiratory failure and acute respiratory distress syndrome in infants and young children". Chinese Medical Journal 125.13 (2012): 2265-2271. 
25. Agarwal R., et al. "Is the mortality higher in the pulmonary vs the extrapulmonary ARDS? A metanalysis". Chest 133.6 (2008):1463-1473.

26. Villar J., et al. "Assessment of $\mathrm{PaO}_{2} / \mathrm{FiO}_{2}$ for stratification of patients with moderate andsevere acute respiratory distress syndrome". BMJ Open 5 (2015): e006812.

27. Villar J., et al. "Age, $\mathrm{PaO}_{2} / \mathrm{FiO}_{2}$, and Plateau Pressure Score: A proposal for a simple outcome score in patients with the acute respiratory distress syndrome". Critical Care Medicine 44.7 (2016):1361-1369.

\section{Volume 2 Issue 10 October 2019}

(C) All rights are reserved by Díaz-Casañas Elaine., et al. 